\title{
Ciberdemocracia: A Internet Como Ágora Digital
}

\author{
Deo Campos Dutra \\ Doutor em Direito pela Université Paris Ouest Nanterre \\ la Défense (Paris X) e pela PUC-Rio. Mestre em Ciências \\ Jurídicas pela PUC-Rio. Mestre em Direito Comparado \\ pela Universidade Paris 1 - Pantheon-Sorbonne. Pós-dou- \\ torado pela École Normale Supérieure/Paris. Professor e \\ coordenador de pesquisa na Faculdade de Direito Doctum \\ (Juiz de Fora, MG, Brasil).deo_campos@yahoo.com.br
}

\section{Eduardo F. de Oliveira Junior}

Bacharel em Direito pela Faculdade de Direito Doctum (Juiz de Fora, MG, Brasil). junior_cantos@yahoo.com.br.

Os autores agradecem aos revisores pela cuidadosa leitura e revisão do texto. As contribuições foram de fundamental importância para este trabalho.

\section{Resumo}

0 advento da era digital modificou a estrutura das relações sociais e políticas da sociedade humana, possibilitando a imediata difusão de ideias e caminhos a se percorrer no que concerne à vida em sociedade. A comunicação instantânea, que fragilizou governos e que tem o condão de reunir indivíduos com interesses semelhantes, também se revela como potencial ferramenta para a expansão do próprio sistema democrático moderno, em que o cidadão goza de meios ativos de participação num sistema integral de democracia, influenciando nas temáticas relevantes de ordem legislativa ou executiva não como espectador político, cuja participação se dá em ciclos predefinidos, mas com atuação constante, uma vez que dispõe de ferramentas para tanto. A forma de governo na qual encontramos uma potencialização da colaboração direta da população com os rumos de seu país e as novas faces da democracia, são o escopo deste estudo.

Palavras-chave: Ciberdemocracia. Democracia. Ciência política. Teoria geral do Estado. Direito digital. 


\title{
Ciberdemocracy: The Internet as the Digital Agora
}

\begin{abstract}
The advent of the digital age has changed the structure of social and political relations of human society, making possible the immediate diffusion of ideas and paths to go through, with regard to the life in society. The instantaneous communication that has weakened governments and which has the capacity to bring together people with similar interests also reveals itself as a potential tool for expanding the modern democratic system itself, where citizen has active ways of participation, in a system of integral democracy, influencing in the relevant subjects of the legislative or executive sphere, not as a political spectator, whose participation is limited to pre-defined four-year cycles, but with constant action since there are tools for that. The form of government in which a population holds the power and collaborates with the direction of its country and the new faces of democracy are the scope of this study.
\end{abstract}

Keywords: Cyberdemocracy. Democracy. Political Science. State general theory. Digital law.

Recebido em: 23/2/2017

Revisões requeridas em: 25/9/2017

Aceito em: 1\%/10/2017

\section{Sumário}

1 Introdução. 2 Da democracia à ciberdemocracia. 3 Ciberdemocracia: do virtual para o real. 4 Ciberdemocracia como ágora moderna. 5 Conclusão. 6 Referências. 


\section{INTRODUÇÃO}

A era digital se funda, em boa parte, na revolução ocorrida nos meios de comunicação, livre dos ruídos analógicos, instantâneos e globalizados, que moldam e se remodelam na estrutura das sociedades modernas. A estreita ligação entre a democracia e a comunicação é auferida desde a $\pi o ́ \lambda \iota \varsigma^{1}$ grega, quando o teatro influenciava, enquanto mídia, ${ }^{2}$ a encenar as questões éticas, políticas e morais, rememorando-se do conceito restritivo de cidadão.

O avanço dos meios de comunicação, desde a escrita, em período mais remoto, passando pelo advento da prensa, que possibilitou a difusão e o transporte das ideias em maior escala, até o surgimento dos primeiros meios eletrônicos após a Revolução Industrial, com ferramentas como os telégrafos e o rádio, causaram impactos e transformações não apenas na estrutura e contexto social, mas, também, na forma da democracia. Hoje, esses impactos são sentidos na era dos computadores interligados pela internet, reputada como a quarta revolução tecnológica (DI FELICE, 2008, p. 22-23).

Após a segunda grande guerra, ferramentas novéis despontaram no horizonte com os computadores, a Arpanet ${ }^{3}$ e o advento da internet, que se tornou importante ferramenta de difusão de ideologias, ${ }^{4}$ construindo

${ }^{1}$ Grego. Transliterado como "Pólis". Cidades-Estado do período clássico da civilização grega.

${ }^{2}$ E, ainda hoje, tanto o teatro quanto todas as manifestações culturais, são mídia, ou seja, meio de comunicação, derivados do mesmo termo latino.

${ }^{3}$ Sistema de comunicação digital militar estadunidense, precursor da internet.

4 Termo entendido no sentido de "conjunto de ideias" ou "edeologia”, conforme a Academia Brasileira de Letras. Disponível em: <http://www.academia.org.br/nossa-lingua/busca-no-vocabulario >. Acesso em: 27 set. 2017. Para compreensão do termo no sentido filosófico e jurídico, sugere-se: SYPNOWICH, Christine. "Law and Ideology". The Stanford Encyclopedia of Philosophy. Edward N. Zalta (Ed.). Disponível em: <https://plato.stanford.edu/ archives/win2014/entries/law-ideology/>. Acesso em: 27 set. 2017. 
espaços de encontro, em que diversas correntes de pensamento podem dialogar, culminando com o ciberespaço, ${ }^{5}$ onde se inserem cibercidadãos, ${ }^{6}$ que podem, entre muitas hipóteses, exercer alguma forma de Ciberdemocracia.

Uma vez permitido amplo alcance e agilidade, os meios digitais anuem com a hipótese da Ciberdemocracia enquanto ferramenta de exercício de democracia direta nas temáticas de maior relevância, equilibrada com o modelo representativo, revestido de transparência no acompanhamento das posturas dos representantes, por parte dos representados, num sistema que realmente reflete as características daquela sociedade na qual se aplique tal modelo.

Nesse cenário, o presente artigo se esteia nas interrogações: Estado e sociedade, modernamente, evidenciam-se capazes de possibilitar o emprego da Ciberdemocracia para a expansão e aprimoramento da democracia, equilibrando a forma direta e representativa? Quais os potenciais riscos auferíveis no referencial teórico analisado? Tais indagações partem da hipótese de que a era digital propicia ferramentas de ampliação da participação popular nas mais relevantes questões sociais, bem como instrumentos no controle da transparência dos atos públicos.

A pesquisa foi desenvolvida pelo método dialético, com abordagem qualitativa, objetivo exploratório e procedimentos bibliográfico e documental. A primeira parte apresenta os elementos históricos e as teorias acerca da temática, observado o vivido e guardada a tese. A segunda parte apresenta as aferições no plano físico, as limitações e os riscos auferidos

\footnotetext{
${ }^{5}$ Sites e aplicativos de telemóvel que permitem espaços de debate ou troca de informações com potencial político.

${ }^{6}$ Indivíduos que utilizam os meios digitais para participação política ou controle da transparência na gestão pública.
} 
da Ciberdemocracia, constituindo a antítese. Na terceira parte, faz-se a ponderação das premissas, obtendo-se o teorema e, por fim, atingindo-se as conclusões.

A Ciberdemocracia, que auxiliou na queda de governos totalitários, inquietou sociedades democráticas e modificou conceitos em seus governos, é o foco deste estudo.

\section{DA DEMOCRACIA À CIBERDEMOCRACIA}

Sob diversos aspectos, biológicos e antropológicos, em princípio, ou econômicos, em momento histórico mais próximo da presente era, o que se aufere nas organizações sociais é que esta evoluiu fundada em sistemas de mando de modo verticalizado, onde há ordenação e subordinação contrapostas, de minorias exercendo a escolha dos rumos sociais e com a maioria populacional submetida aos desígnios destes (RIBEIRO, 1986, p. 16; MOSCA apud DAHL, 1989, p. 27; MARX; ENGELS, 2001, p. 23-24).

A democracia, em sua forma inicial, ateniense, destinava-se aos cidadãos. O conceito era estreito e excluía considerável, senão a maior, parte da população, conforme Maciel e Aguiar (2010, p. 69). Na ágora, decidia-se o rumo da sociedade (FINLEY, 1988).

Não se olvida, contudo, que sua funcionalidade pressupõe e requer a Lei. Para Marvall e Przeworski, a "democracia não pode existir exceto que uma regra, ao menos, seja seguida” (2003, p. 8), e, no mesmo sentido, Ortega y Gasset explica que "democracia e lei - a vida em comum sob a lei - são sinônimos” (1957, p. 17).

A complexidade da democracia reside, contudo, no fato de sua íntima correlação com os diversos campos da compreensão humana, desde a estrutura sociológica e econômica até a esfera tecnológica e comu- 
nicativa, que se relacionam com a arte e a cultura. Ao mirar para a História, percebe-se que o avanço tecnológico, ${ }^{7}$ que implicou avanço social, também modificou a estrutura da democracia.

Di Felice (2008, p. 19) explica que o teatro e as artes, na sociedade ateniense, tinham a função de entreter e, simultaneamente, moldar aspectos políticos, éticos e morais, já evidenciando "todos os elementos" da "política ocidental”. Przeworski et al. (2003, p. 182) observam que "a democracia requer uma base cultural definida" e que "alguma coisa sobre a cultura parece necessária para a democracia emergir ou perdurar", ${ }^{8}$ e Vernant (2002, p. 360-365) explicita que a origem da política se deu, mais do que nas praças, nas competições teatrais, que reuniam os elementos da sociedade grega, da ética e da moral da época, visando a imbuir os cidadãos dos preceitos mais elementares da vida em sociedade.

Os efeitos tecnológicos da época permitiam o momento da chegada do "deus ex machina", envolto em névoas, a representar Zeus, bem como recursos sonoros do coro mascarado ou invisível, no intuito de levar o público à comoção e especular suas opiniões (DI FELICE, 2008, p. 20).

\footnotetext{
${ }^{7}$ Avanço tecnológico, compreendido como todo progresso, oriundo de uma inovação ou invento, com feição inovadora que, uma vez difundido, culmina com o emprego de uma tecnologia - dispositivo ou máquina -, ou novo procedimento, conforme JAFFE, Adam B. et al. Technological Change and the Environment. Resources for the Future, nov. 2001. Discussion Paper 00-47REV. Disponível em: <http://www.rff.org/files/sharepoint/WorkImages/ Download/RFF-DP-00-47.pdf >. Acesso em: 12 jun. 2016; aqui, entende-se no sentido das tecnologias que permitem a transição de uma comunicação analógica, quando emissor e receptor estão apartados, para a comunicação digital na qual estes estão ligados e as mensagens emanadas estão difusas, com diminuição significativa no ruído, no sentido elucidado por DI FELICE, Mássimo. Op. cit. p. 25.

${ }^{8}$ PRZEWORSKI, Adam et al. Culture and democracy. In: DAHL, Robert et al. (Org.). The democracy sourcebook. Massachussetts: MIT Press, 2003. p. 183. Tradução para o trecho: "[...] democracy requires a definite cultural basis [...]" e "Something about culture seems necessary for democracy to emerge or endure".
} 
Como salienta McLuhan (1996, p. 52), os efeitos da tecnologia ultrapassam a opinião e a conceituação, atingindo as relações sensoriais e as estruturas perceptivas.

A primeira grande revolução tecnológica foi a escrita, e outras revoluções, como a prensa e, posteriormente, os meios eletrônicos, com rádio, telégrafos, a massificação da imprensa, o telefone e outros, transformaram a democracia, de modo que, ao fim do século 19, a maioria dos Estados tinha abolido regimes escravocratas e incluído no conceito do termo "cidadão" outras frações sociais (DI FELICE, 2008, p. 22-23) ${ }^{9}$ No século 20, com a ampliação do alcance desses meios tecnológicos, Estados viriam a reconhecer, por exemplo, o direito ao voto feminino, acentuando-se tal tendência após a Primeira Guerra Mundial. ${ }^{10}$

A Segunda Grande Guerra trouxe inovações tecnológicas, com os modelos precursores dos modernos computadores. Ainda no século 20, a velocidade da tecnologia ganharia ritmo acelerado com a Arpanet, desenvolvida para a rápida comunicação entre militares estadunidenses durante a guerra fria, possibilitando os moldes operacionais da internet, hoje largamente difundida e considerada a quarta grande revolução tecnológica (DI FELICE, 2008, p. 22).

Os parâmetros de comunicação digital, propiciados pela Internet, eliminaram os ruídos da forma analógica e tornaram a comunicação mais difusa, influenciando a opinião pública para além dos limites geográficos

\footnotetext{
${ }^{9}$ Esse processo pode ser observado no Brasil, com suas complexidades e especificidades. Ver: CARVALHO, José Murilo de. Cidadania no Brasil: o longo caminho. São Paulo: Civilização Brasileira, 2014.

${ }^{10}$ Para uma crítica a ideia da universalização da cidadania e a mulher, ver: YONG, Iris Marion. Polity and Group Difference: A Critique of the Ideal of Universal Citizenship. In: Ethics: An International Journal of Social, Political and Legal Philosophy, v. 99, n. 2, 1989.
} 
em virtude da globalização, ${ }^{11}$ ocasionando uma alteração ontológica, ${ }^{12}$ afetando a relação do cidadão com o Estado e tornando possível um exercício democrático ampliado, seja pelo ativismo político na internet, nas consultas públicas realizadas ou realizáveis, ou, ainda, num molde tangível de exercício de democracia direta, facilitado pelo emprego da grande rede. Nos ciberespaços em que se permite essa participação, surge a Ciberdemocracia.

Com ganhos e perdas de feições no passar dos séculos, a democracia, como concebemos modernamente, já não assegura, necessariamente, uma correta reverberação dos anseios sociais. Fatores, como o aumento populacional, conduziram à perda do espectro participativo ateniense. As praças do mundo não bastariam e seria inexequível aquele molde, permitindo-se apenas um modelo no qual o cidadão tem uma forma participativa na democracia, em geral, limitada aos momentos eleitorais.

Castells (2010, p. 367-370), nesse cenário, acena com a questão da crise da democracia. Para esse autor, quando se analisam as transformações de um Estado-Nação e dos processos políticos hodiernos, tem-se uma proximidade assaz similar com a realidade do século passado, o que conduz a uma crise não apenas da democracia em si, mas, também, gera

\footnotetext{
${ }^{11} \mathrm{O}$ termo globalização, largamente empregado, mas pouco dotado de conceituações efetivas em razão de sua perene característica flutuante, aqui é compreendido como o processo de interconexão social, econômica e cultural, ou como "growing international interconnectedness - increasing flows of trade, investment and communications between nations", conforme HIRST, Paul; THOMPSON, Grahame. The Future of Globalization. Cooperation and Conflic., v. 37, p. 247-265, 2002. Disponível em: <http://eatonak.org/IPE501/downloads/files/ Hirst_and_Thompson.pdf $>$. Ainda sobre o termo temos que: "Para todos, porém, 'globalização' é o destino irremediável do mundo, um processo irreversivel [...]”, conforme BAUMAN, Zygmunt. Globalização: as consequências humanas. Rio de Janeiro: Zahar, 1999.

${ }^{12}$ Sobre o conceito e a história da ontologia, ver: MEYER, Michel. Pour une histoire de l'ontologie. Paris: PUF, 1999.
} 
uma crise de legitimidade ${ }^{13}$ do Estado-Nação, pela falta de credibilidade de um sistema político que se baseia na competição partidária, posta na esfera midiática, concentrada na figura da liderança, baseada na manipulação por meio de instrumentos tecnológicos sofisticados, tantas vezes, com verbas de campanha adquiridas por meios ilícitos e envolvimentos em escândalos.

Esses fatores, para o autor, corroboram para a perda da confiança e do apelo dos partidos. ${ }^{14}$ Assim, diante das crises de representação, percebe-se que as instituições democráticas existentes vivenciam um esgotamento, sendo necessário que se pense em novas formas para a democracia. ${ }^{15}$

Bobbio (1997), em “O futuro da democracia”, explana sobre as promessas não cumpridas da democracia, verdadeiros óbices a um modelo democrático idealizado, que podem ser compreendidos, primeiro, pela formação de grupos, com interesses comuns, o que, em fato, confronta a concepção individualista da democracia, de uma "sociedade centrípeta",

${ }^{13}$ Conforme o autor: "Let us bring together the various threads we have identified concerning the transformation of the nation-state, and of the political process in contemporary societies. When woven into an historical framework, they reveal the crisis of democracy as we have known it in the past century. The nation-state, defining the domain, procedures, and object of citizenship, has lost much of its sovereignty, undermined by the dynamics of global flows and trans-organizational networks of wealth, information, and power. Particularly critical for its legitimacy crisis is the state's decreasing ability to fulfill its commitments as a welfare state because of the integration of production and consumption in a globally interdependent system, and the related process of apitalist restructuring." CASTELLS, Manuel. The power of identity, the information age: economy, society and culture. Oxford: Wiley-Blackwell, 2010. p. 402.

${ }^{14}$ Conforme se compreende do trecho: "To the crisis of legitimacy of the nation-state we must add the crisis of credibility of the political system, based on open competition between political parties. Captured in the media arena, reduced to personalized leadership, dependent on technologically sophisticated manipulation, pushed into unlawful financing, driven by and toward scandal politics, the party system has lost its appeal and trustworthiness, and, for all practical purposes, is a bureaucratic remainder deprived of public confidence". CASTELLS, Manuel. The power of identity, the information age: economy, society and culture. Oxford: Wiley-Blackwell, 2010. p. 403.

${ }^{15}$ Sobre a questão, ver a entrevista de Manuel Castells para o jornal “O Estado de São Paulo", em 2013. Disponível em: <http://politica.estadao.com.br/noticias/eleicoes, ha-uma-crise-de-legitimidade-do-atual-sistema-politico-diz-castells-imp-,1051538>. Acesso em: 10 jun. 2016. 
posto que temos uma "sociedade centrífuga”. Em segundo lugar, surge a questão da representação, que para este é um dos "princípios mais desconsiderados”, uma vez que o governo, de modo ideal, deveria mediar e garantir o cumprimento da mediação entre os componentes sociais, sem ser imperativo nos interesses próprios, numa "relação triangular".

A persistência das oligarquias, nos moldes conservadores, continua o autor, também se apresenta como barreira, bem como a limitação espacial das tomadas de decisão, considerando que a democracia nos moldes ocidentais modernos não ocupa todos os espaços decisórios. Por fim, Bobbio (1997, p. 21-38) expõe a necessária supressão do "poder invisível”, organizações paralelas que influem no cenário democrático, como a máfia, ou as facções, no caso do Brasil a maçonaria, entre outros exemplos, ${ }^{16}$ devendo haver a maior transparência possível à claridade diurna, permitindo controle, também, da população sobre o poder e, não apenas, o oposto. Ao fim, considera a necessidade da "educação para a cidadania”, a "activae civitatis", reduzindo a apatia política, fazendo o portamento do sujeito passivo político para indivíduo ativo.

Sobre a representação e os momentos de faculdade de escolha, Przeworski (2010, p. 99) leciona que:

O Auto-Governo é exercido por meio de eleições. O processo de tomada de decisão coletivo opera indiretamente: Cidadãos escolhem partidos ou candidatos, autorizando-os a tomar decisões pela coletividade. Mesmo quando os competidores eleitorais apresentam propostas políticas claras, me refiro às plataformas, as alternativas pelas quais os eleitores podem escolher são somente aqueles que são propostas. Nem todas as concebíveis e nem todas as viáveis opções se sujeitam à escolha coletiva. ${ }^{17}$

\footnotetext{
${ }^{16}$ Em algumas circunstâncias, pode-se compreender a atuação da imprensa e do capital.

${ }^{17}$ Tradução para o trecho: "Self-government is exercised through elections. The collective decision-making process operates indirectly: Citizens choose parties or candidates, authorizing them to make decisions on behalf of the collectivity. Even when electoral competitors present
} 
Ainda no tocante à representação, Dahl (1989, p. 29-31) explica que:

Isso não equivale afirmar que os dirigentes políticos e os parlamentos são sempre uma mostra representativa dos distintos extratos sociológicos, ocupacionais, e demais agrupamentos da sociedade. Não são nunca. Nas Câmaras legislativas atuais a classe média e as profissões liberais estão super-representadas numericamente, enquanto que os trabalhadores estão sub-representados (incluindo entre os deputados dos partidos trabalhistas, socialistas e comunistas), o mesmo ocorre com outras categorias: camponeses e donas de casa, por exemplo. Mas mesmo quando a "classe política" não é nunca uma amostra representativa das categorias sociais e econômicas de um país - e muitos defensores da democracia representativa argumentam que não necessitam, nem devem seriamente -, o sufrágio universal junto da rivalidade política dá lugar a parlamentos cujos membros, num sentido puramente estadístico, são em geral mais representativos, individual e politicamente, que em nenhum outro sistema. ${ }^{18}$

Já no que concerne à Ciberdemocracia, observamos que o espírito democrático confronta questões derivadas do próprio avanço tecnológico, cujos impactos alcançam diversas críticas, fundadas em edificações passa-

clear policy proposals, to which I refer as "platforms," the alternatives from which voters can choose are only those that are proposed. Not all conceivable and not even all feasible options become subject to collective choice."

${ }^{18}$ Tradução para o trecho: "Esto no equivale a afirmar que los dirigentes políticos y los parlamentos son siempre una muestra representativa de los distintos estratos sociológicos, ocupacionales, y demás agrupamientos de la sociedad. No lo son nunca. En las Cámaras legislativas actuales la clase media y las profesiones liberales están super-representadas numéricamente, mientras que los obreros están sub-representados (incluso entre los diputados de los partidos laboristas, socialistas y comunistas), lo mismo ocurre con otras categorías: campesinos y amas de casa, por ejemplo. Pero aun cuando la "clase política" no sea nunca una muestra representativa de las categorías sociales y económicas de un país - y muchos defensores de la democracia representativa sostienen que no necesitan, ni deben serlo-, el sufragio universal junto con la rivalidad política dan lugar a parlamentos cuyos miembros, en el sentido puramente estadístico, son en general más representativos, individual y políticamente, que en ningún otro sistema.”. 
das, que "deram aquilo que podiam dar, agora são dispositivos retesados a bloquear a potencialidade daquilo que contribuíram para criar" (ABRUZZESE, 2006, p. 35).

Traçado tal cenário, em epifania, num tempo em que a internet sequer possuía o alcance moderno, Bobbio versava acerca da impossibilidade de se governar mediante contínua participação popular, mas cogitava a hipótese futura da transmissão de votos dos cidadãos para um "cérebro eletrônico”, de modo remoto e simplificado (1997, p. 53-54). E, para além das perspectivas de democracia direta ou representativa, Bobbio atentava para os matizes intermediários e a possibilidade do que denominava “democracia integral”, equilibrando as formas, "todas e cada uma delas”, conforme a situação, uma vez que a lógica não as exclui, ao contrário, possibilita intersecções (1997, p. 52-53).

Com a recente popularização da internet, forma-se um novo modelo, no qual a comunicação e a difusão de ideias políticas e sociais correm com a mesma velocidade de seu instrumento, a grande rede de computadores. Surge o ciberespaço e, inserido neste, o cibercidadão, ${ }^{19} \mathrm{e}$, também, junto, as possibilidades de equilíbrio entre as formas de exercício democrático, as ferramentas auxiliadoras no aprimoramento sociopolítico, com a atuação participativa ou deliberativa, ou no controle do poder público, como se vê em Serraglio e Zanbam (2016, p. 126-130) e Magrani (2010, p. 99).

Na percepção de pesquisadores, a internet possibilita a globalização do próprio indivíduo, tendo “o mundo no seu bolso" e em posição de disponibilidade "ao mundo inteiro", culminando na impossibilidade de que tal fato - a digitalização das relações humanas - não influencie na esfera política, "favorecendo o indivíduo" (DE KERCKHOVE, 2008, p. 127).

\footnotetext{
${ }^{19} \mathrm{O}$ termo cibercidadão tem aqui o sentido empregado por De Kerckhove (2008, op. cit) e Di Felice (2008, Op. cit.), para designar o cidadão que exerce meios participativos utilizando a tecnologia, isto é, o cidadão elevado à era digital, que utiliza o espaço virtual para o exercício da democracia.
} 
Ao mesmo tempo, um importante conceito pode ser retirado das ponderações de Habermas (1997, p. 93): a ideia de esfera pública. Para o autor,

Existem metáforas arquitetônicas para caracterizar a infra-estrutura de tais reuniões, organizações, espetáculos, etc.: empregam-se geralmente os termos "foros", "palcos", "arenas”, etc. Além disso, as esferas públicas ainda estão muito ligadas aos espaços concretos de um público presente. Quanto mais elas se desligam de sua presença física, integrando também, por exemplo, a presença virtual de leitores situados em lugares distantes, de ouvintes ou espectadores, o que é possível através da mídia, tanto mais clara se toma a abstração que acompanha a passagem da estrutura espacial das interações simples para a generalização da esfera pública. ${ }^{20}$

Com tal em mente, é possível compreender que a internet se trata de uma nova esfera pública, tendo o condão de mediar Estado e sociedade e promover debates. Nessa reflexão, podemos entender que a nova esfera pública "se dá pela construção de protocolos de comunicação entre diferentes processos de comunicação”, algo cognoscível nas redes digitais (CASTELLS, 2009, p. 125). Uma plataforma virtual, como o Youtube, por sua vez, mostra-se como um "facilitador de encontros de diferenças culturais e do desenvolvimento do 'ouvir' político através de sistemas de crenças e identidades” (BURGESS; GREEN, 2009, p. 77).

Desta maneira, a comunicação possível na internet pode conduzir ao oposto do que fomenta o totalitarismo, que se firma por meio do "caráter vertical e unidirecional dos fluxos de notícias” e, acentua o autor, que: "Estamos descobrindo que a potência é associada à transparência, como o poder à opacidade” (LÉVY, 2004, p. 32).

${ }^{20}$ Para uma maior compreensão do pensamento do autor alemão, ver: MÜLLER-DOOHM, Stefan. Habermas: A Biography. Cambridge: Polity, 2016. 
Feinmann (2013, p. 431) explica que "a mass media”, categoria em que se apresenta a internet, "não cria nenhuma sociedade transparente", por outro lado, "em uma nova sociedade livre", propiciada pelas novas mídias, "os meios garantirão a transparência democrática”; ${ }^{21}$ isso em virtude fluxo horizontal e multidirecional típico da ferramenta.

De Kerckhove (2008, p. 135-136), por sua vez, atenta para a questão da transparência e redução da estrutura dispendiosa da burocracia. Em sua visão, o e-government disponibiliza a maior parte dos serviços on-line, reduzindo o aparato burocrático e conferindo maior transparência nos trâmites administrativos.

A transparência diurna e o conhecimento do poder por parte da população, com tudo à luz do dia, permitem o conceito do Estado como “naked corporation" (DE KERCKHOVE, 2008, p. 135-136), uma corporação despida do sigilo sobre a gestão dos recursos e dos rumos sociais, que declara o que possui ao se desnudar, enquanto "parecerão estúpidos" os que não agirem desse modo. Estes sistemas têm se popularizado no mundo e, hoje, diversos serviços são realizáveis pela grande rede, inclusive no Brasil, onde é possível, dentre outras coisas, ter acesso às contas públicas, viabilizando maior controle e transparência.

Em um contexto de crise da democracia, ${ }^{22}$ o cidadão, cada vez mais em busca de transparência na gestão dos aspectos públicos, tem ao seu alcance as novas tecnologias e mídias que, uma vez acessíveis, tornam-se instrumentos de controle da gestão do que é público. Com a aparição do

\footnotetext{
${ }^{21}$ Tradução para o trecho: "[...] los mass media no crean ninguna sociedad transparente. [...] en la nueva sociedad libre, los medios garantizan la transparencia democrática”.

${ }^{22}$ Sobre a crise da democracia, ver, entre outros: POSNER, Richard A. The Crisis of Capitalist Democracy. Harvard: Harvard University Press, 2011. Para uma outra perspectiva teórica sobre o tema, ver: AGAMBEN, Giorgio; BADIOU, Alain et al. Démocratie, dans quel état? Paris: La Fabrique, 2009.
} 
cibercidadão, suas ações se direcionam do plano digital para o físico, a modelar a estrutura em que se insere. Surge, com isso, a possibilidade real da aparição de uma verdadeira Ciberdemocracia. ${ }^{23}$

\section{CIBERDEMOCRACIA: Do Virtual Para o Real}

Desde as primeiras feições da Ciberdemocracia no plano físico, resta evidenciado que a comunicação imediata se antagoniza com o poder demasiadamente vestido e opaco - a concepção de arcana imperii ${ }^{24}$ - que sustenta regimes totalitários.

Observa-se, assim, o ocorrido nas Filipinas no período da Lei Marcial do presidente Joseph Estrada.$^{25}$ No Colégio Filipino havia uma publicação jornalística, de oposição ao regime, denominada "mosquito press". $\mathrm{O}$ alcance das críticas ao governo, antes das tecnologias digitais, era pequeno, guardando enorme risco. Com o advento dos telefones móveis e da internet, a "mosquito press" ganhou força, desnudando irregularidades daquele governo e culminando com a designada "Revolta do SMS", que ocasionou a queda do regime, conforme lição de Kerckhove (2008, p. 127-128).

Aqui se vê que as novas mídias propiciam a inversão da ideia do homem subordinado de modo austero ao Estado, mas, pelo contrário, de o Estado refletir os anseios sociais, sob monitoramento dos cidadãos, sujeitos ativos (SERRAGLIO; ZAMBAM, 2016, p. 132).

\footnotetext{
${ }^{23}$ Para uma perspectiva crítica sobre a democracia, que pode ser estendida à Ciberdemocracia, ver: ZAGREBELSKY, G. A crucificação e a democracia. São Paulo: Saraiva, 2012.

${ }^{24}$ Cf. BOBBIO, Norberto. O futuro da democracia. Rio de Janeiro: Paz e Terra, 1997. p. 29.

${ }^{25}$ De 1998 até 2001.
} 
O aumento do alcance das redes globalizadas, resultaram num marco histórico da corrente década. Regimes totalitários e afins, tornaram-se alvos de uma forma da Ciberdemocracia, que atingiu o eixo denominado pan-árabe, como explica Rosiny (2012, p. 1), com a autoimolação do vendedor tunisiano Mohammed Bouaziz, dando início à "Primavera Árabe”, manifestação popular nos países do norte da África e oeste da Ásia, "varrendo" governos despóticos estabelecidos.

Becker e Hüsser (2012, p. 7) explicam que todas as diretrizes das manifestações populares da "Primavera Árabe" se deram pelos meios digitais, por postagens no Facebook, Twitter, mensagens de textos e similares, pelos quais se difundiam os próximos passos e os locais de ação, restando evidenciado que a ocorrência da "Primavera Árabe" deveu-se aos meios digitais de comunicação, à Internet e ao tipo de demanda democrática que tais ferramentas possibilitam.

Apesar de séculos de orientalismo ${ }^{26}$ e desqualificação, por parte de alguns estudiosos, do povo árabe para a democracia, este comprova seu potencial para as instituições democráticas por meio da Ciberdemocracia. Conforme Clemesha et al. (2011, p. 5), é visível que os povos árabes estão "preparados para lutar até o fim por sua liberdade, por democracia e pelo respeito aos seus direitos sociais e humanos”, declarando, ainda, que, mesmo que surja um novo modelo governamental em apenas um dos 22 países árabes envolvidos no movimento, já representará algo vultuoso para a região.

No plano pátrio, em junho de 2013 as redes sociais mobilizaram cidadãos brasileiros. As reivindicações de estudantes e trabalhadores contra o aumento nas tarifas de ônibus, em diversas capitais brasileiras, foram o estopim de uma demonstração de insatisfação generalizada com

\footnotetext{
${ }^{26}$ A terminologia orientalismo tem, aqui, o sentido alcunhado por SAID, Edward. Orientalismo - o Oriente como invenção do Ocidente. São Paulo: Companhia das Letras, 2007.
} 
as formas de gestão pública na democracia brasileira. Uma multidão de brasileiros, de todas as idades, invadiu as ruas das principais cidades do país nas manifestações que entrarão para a história nacional como as “Revoltas de Junho”. Assim, podemos afirmar que o movimento brasileiro mitigou o espaço da mídia tradicional na especulação sociopolítica, permitindo novos canais de expressão, portadores das vozes das ruas (NOBRE, 2013, p. 10). ${ }^{27}$

Nos casos ilustrativos, são sabidos os inúmeros desfechos violentos que ocorreram nas manifestações conclamadas no plano digital e realizadas no plano físico. Arendt, observa, contudo que: "guerras e revoluções, não o funcionamento dos governos parlamentares e o aparato dos partidos democráticos, modelaram as experiências políticas básicas do século vinte" (2005, p. 191). ${ }^{28}$ O que se apresenta como novidade são os meios de convocação, organização e cobertura dos eventos, pautados pela cultura da tecnologia digital. A cibercultura ${ }^{29}$ é o aspecto novo.

As proporções das manifestações no Brasil, como evidenciado, desnudam a questão da Ciberdemocracia, da ânsia de o cidadão ser mais do que participante de uma democracia eleitoral, mas um ator da política, de uma forma protagonista, ou, ainda, conforme Ortega y Gasset, “a

\footnotetext{
${ }^{27}$ Devendo-se considerar as críticas traçadas por AVRITZER, Leonardo. Impasses da Democracia no Brasil. Rio de Janeiro: Civilização Brasileira, 2016.

${ }^{28}$ Tradução para o trecho: "Wars and revolutions, not the functioning of parliamentary governments and democratic party apparatuses, have shaped the basic political experiences of the twentieth century".

${ }^{29}$ Termo empregado para designar o complexo cultural que se desenvolve, de modo aberto e mutável, por meio das redes digitais, conforme LÉVY, Pierre. Cibercultura. São Paulo: Editora 34, 1999.
} 
massa resolveu avançar para o primeiro plano da vida social, para ocupar os lugares, para usar os instrumentos e para gozar dos prazeres até agora reservados a poucos" $\left(1957\right.$, p. 16-17) ${ }^{30}$

Ao falar de tal temática, de aproveitar os instrumentos, lugares e prazeres, no plano real é mais bem vislumbrado quando do exemplo da Estônia, na Europa Setentrional, que se tornou pioneira na aplicação da democracia digital ao instituir o sistema de votação online, em tese, a práxis sugerida por Bobbio, a transmissão do voto a um cérebro eletrônico.

Drechsler (2004, p. 12) narra que a ideia foi defendida na Estônia pelo Primeiro Ministro Laar, e questionada no Parlamento a possibilidade de testar o modelo, resultando na aplicação de testes ainda no mesmo ano, em $2002 .^{31}$

Os cidadãos estonianos possuem, obrigatoriamente, um título de eleitor com um chip, adaptado para o sistema do e-voting. Em 2007, o sistema de votação on-line, para escolha dos parlamentares naquele ano, contou com a adesão de 30 mil $^{32}$ eleitores digitais. Em 2013, a Inglaterra demonstrou interesse em aderir ao sistema da Estônia, a flertar com os sistemas de voto pelas novas mídias, como a internet e as mensagens de texto. $^{33}$

\footnotetext{
${ }^{30}$ ORTEGA Y GASSET, José. The revolt of masses. Nova Iorque: W. W. Norton \& Company, 1957. p. 17. Tradução para o trecho: "[...] the mass has decided to advance to the foreground of social life, to occupy the places, to use the instruments and to enjoy the pleasures hitherto reserved to the few."

${ }^{31}$ Tradução para o trecho: "The idea of e-voting was thus strongly promoted by Prime Minister Laar, who in the Parliamentary question time [...], proposed the idea of testing e-voting during the same year and to decide then whether to introduce it already for the 2002 local elections".

${ }^{32}$ Cf. Terra Notícias. Disponível em: <http://tecnologia.terra.com.br/internet/estonia-e-primeiro- pais-a-votar-pela-internet,c6a85295fb6ea310VgnCLD200000bbcceb0aRCRD.html>.

${ }^{33} \mathrm{Cf}$. The Telegraph. Disponível em: <http://www.telegraph.co.uk/news/politics/conservative/ 10232676/britain-should-follow-Estonias-lead-on-voting-says-Bercow.html>.
} 
Considerando a posição de Przeworski (2010, p. 171), de que a existência das ferramentas viáveis não implica em sua utilização, verifica-se que, no Brasil, as possibilidades de Ciberdemocracia esbarram em ponto bastante sensível: a inclusão digital.

De acordo com dados do IBGE, ${ }^{34}$ veiculados pelo governo federal, ${ }^{35}$ é possível obter os seguintes dados:

\section{Gráfico 1 - Inclusão Digital no Brasil}

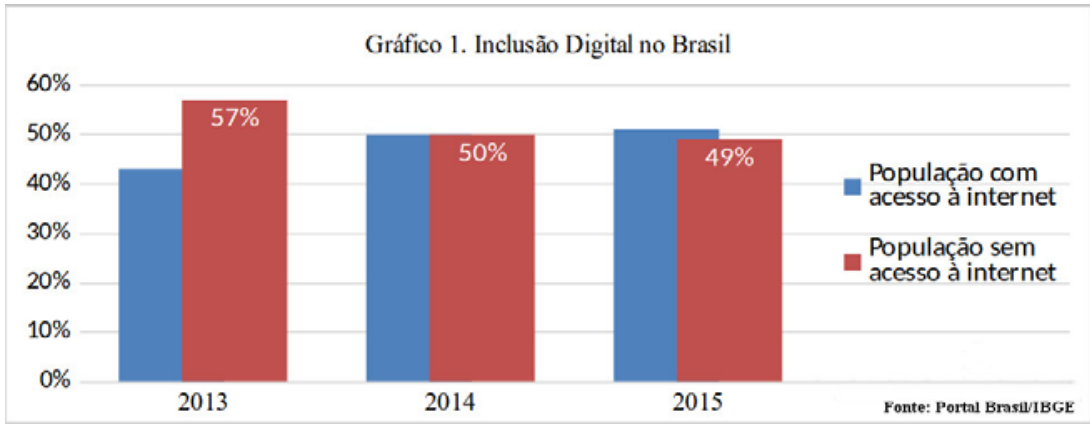

Fonte: BRASIL, 2016.

De tais dados, o que se denota é que, apesar da crescente inclusão nos últimos anos, ainda há um caminho longo a se percorrer, sendo arriscado falar em democracia integral por meio de Ciberdemocracia, uma vez que a democracia exige $51 \%$ da totalidade, algo inatingível nesse cenário, que exclui cerca de outros 100 milhões de brasileiros.

Em pesquisa empírica, Best e Wade (2005, p. 17-18), elencam alguns quesitos que podem mitigar as potencialidades da Ciberdemocracia, pertencentes ao campo das regulações arquitetônicas, no próprio código de

\footnotetext{
${ }^{34}$ Instituto Brasileiro de Geografia e Estatística.

${ }^{35}$ BRASIL. Pesquisa revela que mais de 100 milhões de brasileiros acessam a internet. 2016. Disponível em: <http://www.brasil.gov.br/ciencia-e-tecnologia/2016/09/pesquisa-revela-que-mais-de-100-milhoes-de-brasileiros-acessam-a-internet> Acesso em: 10 fev. 2017.
} 
softwares e sistemas, divididos em duas categorias: softwares de criptografia e de filtragem. Os softwares de criptografia, por um lado, corroboram com a Ciberdemocracia, uma vez que permitem aos grupos excluídos da participação um diálogo secreto e livre de controle estatal, contudo alertam os estudiosos que "isso minará regimes ditatoriais e conduzirá a novos excessos”, justamente por estar à margem de qualquer controle.

Por seu turno, os softwares de filtragem restringem o acesso da população a determinados websites ou serviços, sendo ferramenta de controle e monitoramento da rede, como fazem países da Ásia, como China e Singapura. Os mesmos autores ainda revelam que o preço de mercado do acesso à internet é também um obstáculo, algo que dificulta a inclusão digital.

O controle, podemos denotar, é um elemento de descaracterização do empoderamento do cidadão no ciberespaço, ainda sob os riscos de transformar as novas mídias em algo superficial.

Marcuse (1973, p. 18) vertia sua crítica a um modelo tecnológico que deixa de ser ferramenta de aprimoramento social para se transformar em mero instrumento de controle social. Declarava esse autor que:

A nossa sociedade se distingue por conquistar as fôrças sociais centrífugas mais pela Tecnologia do que pelo Terror, com dúplice base numa eficiência esmagadora e num padrão de vida crescente. [....] A tecnologia serve para instituir formas novas, mais eficazes e mais agradáveis de controle social e coesão social.

A respeito da opção pela tecnologia, ao invés do terror, Arendt (2005, p. 68-69) explica que “o medo, propriamente dito, não é um princípio de ação, mas um princípio antipolítico”. Ainda assim, a tecnologia é uma potencial Ciberdemocracia, em que, presente o controle social, pode criar um cenário no qual o "medo das tiranias" culmina em uma estrutura limitada, como visto em alguns países, o que, para esta cientista política, "trata-se de uma democracia pervertida”, que age de modo díspar e reduz a parca força dos párias. 
Hardt e Negri (2002, p. 278) consideram ainda que há:

[...] uma centralização intensa do controle instrumentado (de fato ou de direito), mediante a unificação dos principais elementos que formam a estrutura do poder de informação e da comunicação: Hollywood, Microsoft, IBM, AT\&T, etc. As novas tecnologias de comunicação que haviam prometido uma nova democracia e uma igualdade social, em verdade, criaram novas linhas de desigualdade e exclusão, não só nos países dominantes, mas também e especialmente fora deles. ${ }^{36}$

Outro ponto relevante que tolhe a universalidade da participação ciberdemocrática para além das políticas de inclusão digital, reside na alfabetização geral e com vistas à inclusão digital. De acordo com dados do IBGE, ${ }^{37}$ podemos extrair os seguintes dados, para a população com 15 anos ou mais, analfabeta:

\section{Gráfico 2 - Analfabetismo no Brasil}

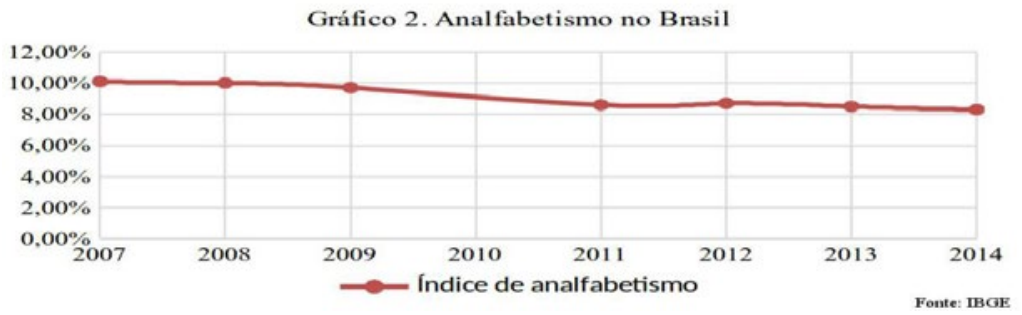

Fonte: BRASIL, 2017.

\footnotetext{
${ }^{36}$ Tradução para o trecho: “[...] una centralización intensa del control instrumentada (de facto o de jure) mediante la unificación de los principales elementos que conforman la estructura de poder de la información y la comunicación: Hollywood, Microsoft, IBM, AT\&T, etcétera. Las nuevas tecnologías de la comunicación que habían prometido una nueva igualdad social, en realidad crearon nuevas líneas de desigualdad y exclusión, no solo en los países dominantes, sino también y especialmente fuera de ellos."

${ }^{37}$ Conforme dados do IBGE. Disponível em: <http://brasilemsintese.ibge.gov.br/educacao/ taxa-de- analfabetismo-das-pessoas-de-15-anos-ou-mais.html>. Acesso em: 10 fev. 2017.
} 
Tornando os porcentuais mais humanos, os $8,3 \%$ de analfabetos, registrados em 2014, compreendem, aproximadamente, 16,8 milhões de pessoas. ${ }^{38}$ Sob tal perspectiva, o direito de participar e influenciar na sociedade, historicamente conquistado, em hipótese de exercício por via digital, obstaria com maior propósito essa camada, posto que o uso das ferramentas de Ciberdemocracia pressupõe a alfabetização.

Convém ainda lembrar que, havendo, também, a necessidade de interpretação sensorial perceptiva, conforme observa Eco (2000, p. 29), “diferentes sintaxes e léxicos” podem reger a comunicação, ou, nota-se, nas palavras de Eco (2000, p. 208), que certos signos gráficos que substituem os vocábulos apenas têm sua semântica no contexto que pertencem. Assim, alguns signos e gráficos usados na comunicação digital pertencem a um sistema semiótico próprio do campo cibernético e demandam adaptação para seu uso.

Em 2016, a eleição de Donald Trump esteve envolta em ações que refletem as questões digitais, desde possíveis ciberataques a sua rival, Hillary Clinton, o que questiona a segurança das redes para fins democráticos, ${ }^{39}$ até os algoritmos das redes sociais que, virtualmente, podem ter favorecido o candidato republicano. ${ }^{40}$

De acordo com o pesquisador de psicometria Michal Kosinski, é possível traçar, com boa margem de acerto, o perfil psíquico das pessoas baseando-se nas páginas do Facebook que cada indivíduo "curtiu”. Assim, por exemplo, pessoas que curtem o músico Bob Dylan tendem

\footnotetext{
${ }^{38}$ Considerando $8,3 \%$ da estimativa populacional do IBGE para 2014, fixada em 202,7 milhões de habitantes.

${ }^{39} \mathrm{Cf}$. INKSTER, Nigel. Information Warfare and the US Presidential Election. In: Survival Global Politics and Strategy, vol. 58, Issue 5, p. 23-32, 2016.

${ }^{40}$ GRASSEGGER, Hannes; KROGERUS, Mikael. The Data That Turned the World Upside Down. Disponível em: <https://motherboard.vice.com/en_us/article/how-our-likes-helped-trump-win>. Acesso em: 10 fev. 2017.
} 
a ser menos tradicionalistas, enquanto fãs da banda Mettalica tendem a ser conservadores, de acordo com a metodologia traçada. ${ }^{41} \mathrm{Com}$ as correlações, muitas vezes aparentemente desconexas, o público estará muito mais propenso a ver determinadas publicações em detrimento de outras, formando as já notórias bolhas ideológicas que reforçam estigmas e inculcam posicionamentos e ações.

Tais fatos e teorias desvelam a face negativa da Ciberdemocracia, usada como ferramenta de controle, sujeita a riscos de invasões e modificações de dados, ou, ainda, causando o fracionamento social em razão de algoritmos que segregam. Tem-se, contudo, a expectativa percebida em Adorno (2006, p. 131-132), de que a tecnologia permite pessoas "afiadas com a técnica”, quiçá, "menos influenciáveis”, livres de tal cariz "patogênico”, como um "véu tecnológico”.

\section{CIBERDEMOCRACIA COMO ÁGORA MODERNA}

A tecnologia e a internet estão, hoje, no bolso de milhões de pessoas. A cultura de seu uso já possibilita impactos factuais na esfera sociopolítica em diversos países, inclusive no Brasil.

Hoje, a internet é a ágora e o teatro digital, onde os temas, relevantes às sociedades, são debatidos e, ao mesmo tempo, dramatizados no intuito de criar posições nos cibercidadãos. O que a Ciberdemocracia pode proporcionar é uma amplificação da participação popular nas tomadas de decisão políticas para os mais variados pontos.

\footnotetext{
${ }^{41}$ Usuários da rede social Facebook podem participar e ter acesso às características detalhadas do perfil comportamental pelas páginas que acompanham, compreendendo a métrica no site da pesquisa. The Psychometrics Centre, Univerty of Cambridge. Disponível em: $<$ https://applymagicsauce.com>.
} 
Magrani (2014, p. 87) entende que a política participativa é possível fora das redes digitais, contudo estas facilitam, desde a propositura legislativa popular até a mera difusão de teorias ou ideologias políticas em artigos ou redes sociais, majorando a capacidade de influência.

O mesmo autor aponta a experiência brasileira com o "Portal da e-Democracia”, espaço destinado aos atores sociais para colaborarem com a Câmara dos Deputados, desde a formulação de leis até o uso das ferramentas de fiscalização e transparência (MAGRANI, 2014, p. 70). A ideia de colaboração é também sustentada e apontada como viável por Côté (2004, p. 23), bem como por Lévy (1999, p. 130), ao entender que as novas formas de comunicação formam "processos abertos de colaboração".

Com razão, diversas organizações políticas pelo mundo adotam alguma forma de participação do cibercidadão num modelo de democracia como "obra aberta”, que "podemos definir como obras em movimento", ou, ainda, como "obras nas quais o receptor colabora efetivamente para uma criação do objeto estético” (ECO, 1970, p. 39).

Uma vez existindo o potencial apreendido, deve-se compreender os meios práticos de mitigar os efeitos eventualmente nocivos dantes explicitados por estudiosos e pelos fatos, considerando que o mais radical reside na alfabetização integral da população, pressuposto básico para a utilização das novas tecnologias de expressão do cibercidadão, possibilitando indivíduos afinados com a técnica, como ansiara Adorno (2006), exigindo ação do poder público para tal feito. Na contramão da história, e em direção aos seus interesses, o governo federal recentemente suspendeu o programa federal de erradicação ao analfabetismo. ${ }^{42}$

\footnotetext{
${ }^{42} \mathrm{Cf}$. PINHO, Ângela. Governo Temer suspende programa nacional de combate ao analfabetismo. In: Folha de São Paulo. Disponível em: <http://www1.folha.uol.com.br/educacao/2016/08/1807683-governo-temer-suspende-programa-nacional-de-combate-ao-analfabetismo.shtml>. Acesso em: 11 fev. 2016.
} 
A inclusão digital se dá na mesma proporção para um sistema de democracia integral. Como o sugerido, as ferramentas devem se tornar disponíveis para além de metade da população, pois, novamente, não se há de dizer de exercício democrático de frações, no século 21 , conquistada a universalidade. Best e Wade (2005, p. 18-19) explicitam que os indicadores acenam com a tendência de gradual queda nos valores, o que, por conseguinte, ampliaria o acesso, ressalvando que os governos podem contribuir com ações ligadas ao uso da internet, com vistas a manter parte da população longe do acesso às ferramentas de Ciberdemocracia.

No que concerne ao controle social exercido, há dados que demonstram que quanto maior o acesso às mídias digitais mais se eleva a pontuação no índice democrático, uma vez que, livre de ferramentas de filtragem, controladas pelo Estado, há possibilidade de acesso a todo tipo de conhecimento disponível (BEST; WADE, 2005, p. 19-21).

Ao mesmo tempo, a criação de sistemas de participação seguros, haja vista a possibilidade de vazamento ou modificações na expressão da vontade, modernamente, já não esbarra em grandes óbices. Os softwares de criptografia, antes explicitados, são teoricamente invioláveis sob o sistema de 256 -bits de criptografia. ${ }^{43}$ Arora (2012) explica que as possibilidades de combinações pela criptografia com 256-bits são representadas numericamente por $1.1 \times 10^{77}$, cujo tempo para se conseguir quebrar seria expressado por $3.31 \times 10^{56}$ anos, resultando em números tão grandes que superam a própria idade do universo. Em suma, sistemas seguros de Ciberdemocracia são factíveis.

\footnotetext{
${ }^{43}$ Como exemplo, há o caso dos Discos Rígidos do banqueiro Daniel Dantas. Cf. <http:// g1.globo.com/politica/noticia/2010/06/nem-fbi-consegue-decifrar-arquivos-de-daniel-dantas-diz-jornal.html>.
} 
Iniciativas nesse sentido são abundantes ao redor do globo. A União Europeia mantém o site Your-Voice in Europe, ${ }^{44}$ visando a promover consultas populares e debates que influem na sociedade e, no mesmo sentido, a cidade de Ottawa, ${ }^{45}$ no Canadá, passou a adotar a e-democracy, disponibilizando uma série de serviços on-line, além da possibilidade de participação em debates e consultas que norteiam a gestão pública.

No Brasil, a prefeitura de Belo Horizonte foi pioneira ao lançar, em 2006, o site do Orçamento Participativo, ${ }^{46}$ em que os cidadãos colaboravam no processo de gestão da cidade. $\mathrm{O}$ website Update Politcs ${ }^{47}$ realizou, recentemente, o mapeamento e indexação das iniciativas de Ciberdemocracia na América Latina, apontando para plataformas nas quais o cibercidadão pode participar dos rumos e diretrizes de seu Estado, desde uma atuação no controle da transparência até a cultura e comunicação política.

A partir das manifestações, ocorridas em 2013, o Senado disponibilizou, após sanção da Resolução n. 26, do mesmo ano, ferramentas, ainda tímidas, de participação em enquetes, cujos resultados acompanham o projeto de lei, dando ciência da vontade popular ao representante político. Ainda para proposição legislativa, houve a instalação do programa e-Cidadania, em 2015.

A demanda que agora se tem, com vastas teorias existentes acerca da Ciberdemocracia como ferramenta de um sistema de democracia integral, repousa na necessidade de comprovação empírica. Para tanto, considerando as proposições, vislumbra-se a possibilidade daquilo que podemos denominar de zonas experimentais de Ciberdemocracia, posto

\footnotetext{
$\overline{{ }^{44} \text { Cf. UNIÃO EUROPEIA. Your-Voice. Disponível em: <http://ec.europa.eu/yourvoice/>. }}$ ${ }^{45}$ Cf. OTTAWA. E-Democracy. Disponível em: <www.ottawa.ca $>$.

${ }^{46}$ Cf. PREFEITURA DE BELO HORIZONTE. Orçamento Participativo. Disponível em: $<$ http://portalpbh.pbh.gov.br/pbh/ecp/comunidade.do?app=portaldoop>.

${ }^{47}$ Cf. UPDATE POLITCS. Disponível em: <http://updatepolitcs.cc/>.
} 
que os próprios sistemas democráticos se sujeitam a fatores inexatos e subjetivos, que variam, no contexto social, antropológica e culturalmente, e isso implica consideração.

Deve-se evitar, porém, que se incorra na criação de uma "ciberanarquia" e, assim, as localidades, para testar o modelo, mescla de democracia direta e representativa, devem ser aquelas com porte pequeno ou médio e com presença expressiva de digitalização e acesso à internet, o mais próximo possível de 100\% de acesso (CÔTÉ, 2004, p. 24).

Num potencial sistema de testes, além de conclamar o cibercidadão a expressar suas opiniões em enquetes, propor normas jurídicas municipais ou acompanhar a gestão do orçamento, este também participaria votando, por sistemas digitais criptografados, em leis de maior relevância política, em parceria com seus representantes políticos, sendo todos os dados acompanhados para futuros estudos empíricos que comprovarão ou refutarão a tese de efetividade do sistema durante todo um período legislativo, isto é, no Brasil, quatro anos.

\section{CONCLUSÃO}

Do referencial teórico vê-se a intrínseca relação da democracia com diversos campos, em especial com a comunicação, comprovando a máxima aristotélica. Ainda, as evoluções das mídias digitais amplificam os efeitos da comunicação no exercício democrático, dando azo à Ciberdemocracia enquanto ferramenta de democracia, possibilitando o encontro entre as formas direta e representativa, quiçá como o modelo idealizado por Bobbio (1997).

Desde as ágoras e o teatro grego, o próprio conceito de democracia se modificou diversas vezes, atingindo seu aspecto universal, não mais excluindo parcela da população em razão de critérios sexistas, econômicos ou raciais. 
Das muitas ferramentas para o exercício e a participação na democracia, a Ciberdemocracia se apresenta como instrumento capaz de mitigar a apatia na participação política, enfrentando diretamente a crise democrática instalada no globo, movendo o cidadão para o plano protagonista, uma vez que, como observamos, no sistema puramente representativo nem tudo está sujeito à aprovação ou à expressão social, criando sociedades incompatíveis com o contexto sociopolítico que deveriam refletir.

Também se percebe que as ferramentas de Ciberdemocracia têm o condão de limitar o poder desde a efetiva participação, norteando os rumos a se seguir até o controle da transparência e do orçamento.

Nota-se que para uma aplicação efetiva e ampla das ferramentas de Ciberdemocracia diversos e antigos desafios precisam ser enfrentados. Demanda-se ações positivas para alfabetização integral da população, inclusão digital, redução dos custos de acesso e criação de sistemas seguros, criptografados, utilizáveis para a expressão da vontade do cidadão, passos que permitiriam alargar a atividade da cidadania na proposta de democracia integral evidenciada ao longo da pesquisa.

Requer-se, ainda, que o Estado lance mão do emprego extremado de ferramentas de filtragem que limitam a acessibilidade e as comunicações instantâneas, posto que a democracia nas sociedades modernas se evidenciou incompatível com a ideia de arcana imperii.

A questão que se verifica, neste ponto, é que, ampliado o alcance da internet e de formas de Ciberdemocracia, o próprio índice de democratização de uma nação também se eleva.

É inegável que tais ferramentas já impactam as sociedades democráticas de todo o globo e, havendo ainda questões por se resolver para o alcance integral da internet e das ferramentas ora analisadas no 
Brasil, conclui-se que o único modo real e factível de se obter dados que confirmam a potencialidade benéfica explicitada pelo referencial teórico consiste na introdução de zonas experimentais de Ciberdemocracia.

Nessas zonas, os cidadãos, por determinado período, participam também do processo legislativo das temáticas mais relevantes, em parceria com seu representante político, sendo igualmente conclamado a vistoriar o orçamento e a gestão dos bens públicos no exercício do Executivo.

Assim, ao fim de tal termo, poder-se-á aferir os índices de democratização das zonas de teste e, quiçá, progressivamente, expandi-las ao ponto de uma sociedade com sistema democrático integral ou misto, entre democracia direta e representativa, seguindo as observações antes percebidas. Para tanto, um primeiro passo é necessário; passo esse que dará ensejo a novas reflexões, como, por exemplo, no campo da dogmática jurídica e as necessárias alterações legislativas para a aplicação deste novo modelo.

Constatamos, portanto, um complexo caminho a percorrer para a efetivação desse importante instrumento que se mostra não só teoricamente robusto, mas exequível. Há uma oportunidade real para que as novas tecnologias contribuam de maneira decisiva para o aprimoramento dos atuais e questionados sistemas democráticos, e elas devem ser não somente estudadas e refinadas, mas efetivamente executadas.

No tempo em que a democracia enfrenta diversos desafios ao redor do mundo e onde em muitos desses lugares ela está sendo golpeada de forma inquietante por aqueles que juraram a proteger, convém descortinar novas possibilidades e novas formas para a efetivação democrática. Assim, se o futuro do sistema democrático, como hoje o conhecemos, se apresenta de maneira dúbia, nada mais importante que refletir sobre novas formas e instrumentos como aqueles apresentados pela Ciberdemocracia. 


\section{REFERÊNCIAS}

ABRUZZESE, A. L'innovazione tra post-democrazia e post-umanità. In: DE KERCKHOVE, Derrick; TURSI, Antonio (Org.). Dopo la democrazia? Milão: Apogeo, 2006.

ADORNO, Theodor W. Educação e emancipação. Rio de Janeiro: Paz e Terra, 2006.

ARENDT, Hannah. The Promise of Politics. Nova York: Schocken Books, 2005. ARORA, Mohit. How secure is AES against brute force attacks? EE Times. 2012. Disponível em: <http://www.eetimes.com/document.asp?doc_ id=1279619 . Acesso em 11 fev. 2017.

BECK, Martin; HÜSER, Simone. Political change in the Middle East: An attempt to analyze the "Arab Spring". Hamburgo: GIGA Ressearch Unit. $\mathrm{n}^{\circ}$ 203 de 2013. Disponível em: <http://www.giga-hamburg.de/de/system/files/ publications/wp203_beck-hueser.pdf>. Acesso em: 6 nov. 2013.

BAUMAN, Zygmunt. Globalização: as consequências humanas. Rio de Janeiro: Zahar, 1999.

BENJAMIN, Walter. Magia e técnica, arte e política. Obras escolhidas vol. 1. São Paulo: Brasiliense, 1987.

BEST, Michael L.; WADE, Keegan W. The Internet and Democracy: Global Catalyst or Democratic Dud? 2005. Disponível em: $<$ https://cyber.harvard.edu/ wg_home/uploads/ 503/12-InternetDemocracy.pdf . Acesso em: 10 fev. 2017. BOBBIO, Norberto. O futuro da democracia. Rio de Janeiro: Paz e Terra, 1997. BRASIL. Pesquisa revela que mais de 100 milhões de brasileiros acessam a internet. 2016. Disponível em: <http://www.brasil.gov.br/ciencia-e-tecnologia/2016/09/pesquisa-revela-que-mais-de-100-milhoes-de-brasileiros-acessam-a-internet> Acesso em: 10 fev. 2017.

. Instituto Brasileiro de Geografia e Estatística (IBGE). Taxa de analfabetismo das pessoas de 15 anos ou mais. Disponível em: <http://brasilemsintese.ibge.gov.br/educacao/taxa-de- analfabetismo-das-pessoas-de-15-anos-ou-mais.html>. Acesso em: 10 fev. 2017. 
BURGESS, Jean; GREEN, Joshua. YouTube: Online video and participatory culture. Cambridge: Polity Press, 2009.

CASTELLS, Manuel. The power of identity, the information age: economy, society and culture. Oxford: Wiley-Blackwell, 2010.

. Communication Power. Oxford: Oxford University Press, 2009.

CLEMESHA, A. E. et al. Déspotas em retirada: o Ocidente decidiu escolher o islamismo como o anticristo da vez. Jornal da Unicamp, Campinas, ano XXV, n. 486,14 a 20 mar. 2011.

CÔTÉ, François. Parliamentary Institutions and Cyber-democracy. 2004. Disponível em: <http://revparl.ca/27/3/27n3_04e_c\%C3\%B4t\%C3\%A9.pdf> Acesso em: 10 fev. 2017.

DAHL, Robert. A. La poliarquía: participación y oposición. Madri: Tecnos, 1989.

DE KERCKHOVE, Derrick. Da democracia à Ciberdemocracia. In: DI FELICE, Massimo (Org.). Do público para as redes. São Caetano do Sul: Difusão, 2008.

DI FELICE, Massimo. Do público para as redes. São Caetano do Sul: Difusão, 2008.

DRECHSLER. Wolfgang. The Estonian E-Voting Laws Discourse: Paradigmatic Benchmarking for Central and Eastern Europe. University of Tartu, 2004. Disponível em: <http://unpan1.un.org/intradoc/groups/public/documents/ nispacee/unpan009212.pdf>. Acesso em: 6 nov. 2013.

ECO, Umberto. Tratado de semiotica general. Barcelona: Lumen, 2000. . A obra aberta. São Paulo: Perspectiva, 1970.

FINLEY, Moses I. O legado da Grécia. Uma nova avaliação. Brasília: UNB, 1998.

FEINMANN, José Pablo. Filosofía política del poder mediático. Buenos Aires: Planeta, 2013. (Livro digital). 
FUCHS, Christian. Mídias sociais e a esfera pública. In: Revista Contracampo, v. 34, n. 3, ed. dez. 2015/mar. 2016. Niterói: Contracampo, 2015.

GRASSEGGER, Hannes; KROGERUS, Mikael. The Data That Turned the World Upside Down. Disponível em: <https://motherboard.vice.com/en_us/ article/how-our-likes-helped-trump-win>. Acesso em: 10 fev. 2017.

GROSSI, Giorgio. L'opinione pubblica - Teoría del campo demoscópico. Roma: Laterza, 2004.

HABERMAS, Jürgen. Direito e democracia: entre facticidade e validade. Rio de Janeiro: Tempo Brasileiro, 1997. Vol. II.

HARDT, Michael; NEGRI, Antoni. Imperio. Buenos Aires: Paidós, 2002.

HIRST, Paul; THOMPSON, Grahame. The Future of Globalization. Cooperation and Conflic, vol. 37, p. 247-265, 2002. Disponível em: <http://eatonak.org/ IPE501/downloads/files/Hirst_and_Thompson.pdf>. Acesso em: 10 jun. 2016. INKSTER, Nigel. Information Warfare and the US Presidential Election. In: Survival - Global Politics and Strategy, vol. 58, Issue 5, p. 23-32, 2016.

LÉVY, Pierre. Cibercultura. São Paulo: Editora 34, 1999.

. Ciberdemocracia: ensayo sobre filosofia política. Barcelona: Editorial UOC, 2004.

MACIEL, José Fábio R.; AGUIAR, Renan. História do Direito. São Paulo: Saraiva, 2010.

MAGRANI, Eduardo. Democracia conectada: a internet como ferramenta de engajamento político-democrático. Curitiba: Juruá, 2014.

MARCUSE, Herbert. A ideologia da sociedade industrial. Rio de Janeiro: Zahar Editores, 1973.

MARVALL, José María; PRZEWORSKI, Adam. Democracy and the rule of law. Cambridge: Cambridge University Press, 2003.

MARX, Karl; ENGELS, Friedrich. Manifesto do Partido Comunista. Porto Alegre: LP\&M, 2001. 
MATTELART, Armand; MATTELART, Michèle. História das teorias da comunicação. São Paulo: Loyola, 1999.

MCLUHAN, Marshall. Os meios de comunicação como extensões do homem. São Paulo: Cultrix, 1996.

MOSCA, Gaetano. In: DAHL, Robert. A. La poliarquía: participación y oposición. Madri: Tecnos, 1989.

NOBRE, Marcos. Choque de democracia: Razões da revolta. São Paulo: Companhia das Letras, 2013.

ORTEGA Y GASSET, José. The revolt of the masses. Nova York: W. W. Norton \& Company, 1957.

PRZEWORSKI, Adam et al. Culture anda Democracy. In: DAHL, Robert et al. (Org.). The Democracy Sourcebook. Massachusetts: MIT Press, 2003.

PRZEWORSKI, Adam. Democracy and the limits of Self-Government. Cambridge: Cambridge University Press, 2010.

RIBEIRO, J. Ubaldo. Política. Quem manda, por que manda, como manda. Rio de Janeiro: Nova Fronteira, 1986.

ROSINY, Stephan. The Arab Spring: triggers, dynamics and prospects. Hamburgo: Giga Ressearch Unit., n. 1 de 2012. Disponível em: <http://www. giga-hamburg.de/de/system/files/publications/gf_international_1201.pdf>. Acesso em: 6 nov. 2013.

SERRAGLIO, Priscila Z.; ZAMBAM, Neuro J. Democracia e internet: pensando a limitação do poder na sociedade da informação. In: Direito, Estado e Sociedade, PUC-Rio, n. 49, p. 114-141, jul./dez. 2016. Disponível em: <http:// www.jur.puc-rio.br/revistades/index.php/revistades/article/view/468/440>. Acesso em: 10 fev. 2017.

VERNAT, Jean-Pierre. Entre mito e política. São Paulo: Edusp, 2002. 